This item was submitted to Loughborough's Research Repository by the author.

Items in Figshare are protected by copyright, with all rights reserved, unless otherwise indicated.

\title{
Promoting stair climbing: intervention effects generalize to a subsequent stair ascent
}

PLEASE CITE THE PUBLISHED VERSION

http://healthpromotionjournal.com/mm5/merchant.mvc?

Screen=PROD\&Store_Code=AJHP\&Product_Code=JV22I2114\&Category_Code=

\section{PUBLISHER}

(C) American Journal of Health Promotion, inc.

\section{VERSION}

AM (Accepted Manuscript)

\section{LICENCE}

CC BY-NC-ND 4.0

\section{REPOSITORY RECORD}

Webb, Oliver J., and Frank F. Eves. 2019. "Promoting Stair Climbing: Intervention Effects Generalize to a Subsequent Stair Ascent". figshare. https://hdl.handle.net/2134/8926. 
This item was submitted to Loughborough's Institutional Repository (https://dspace.lboro.ac.uk/) by the author and is made available under the following Creative Commons Licence conditions.

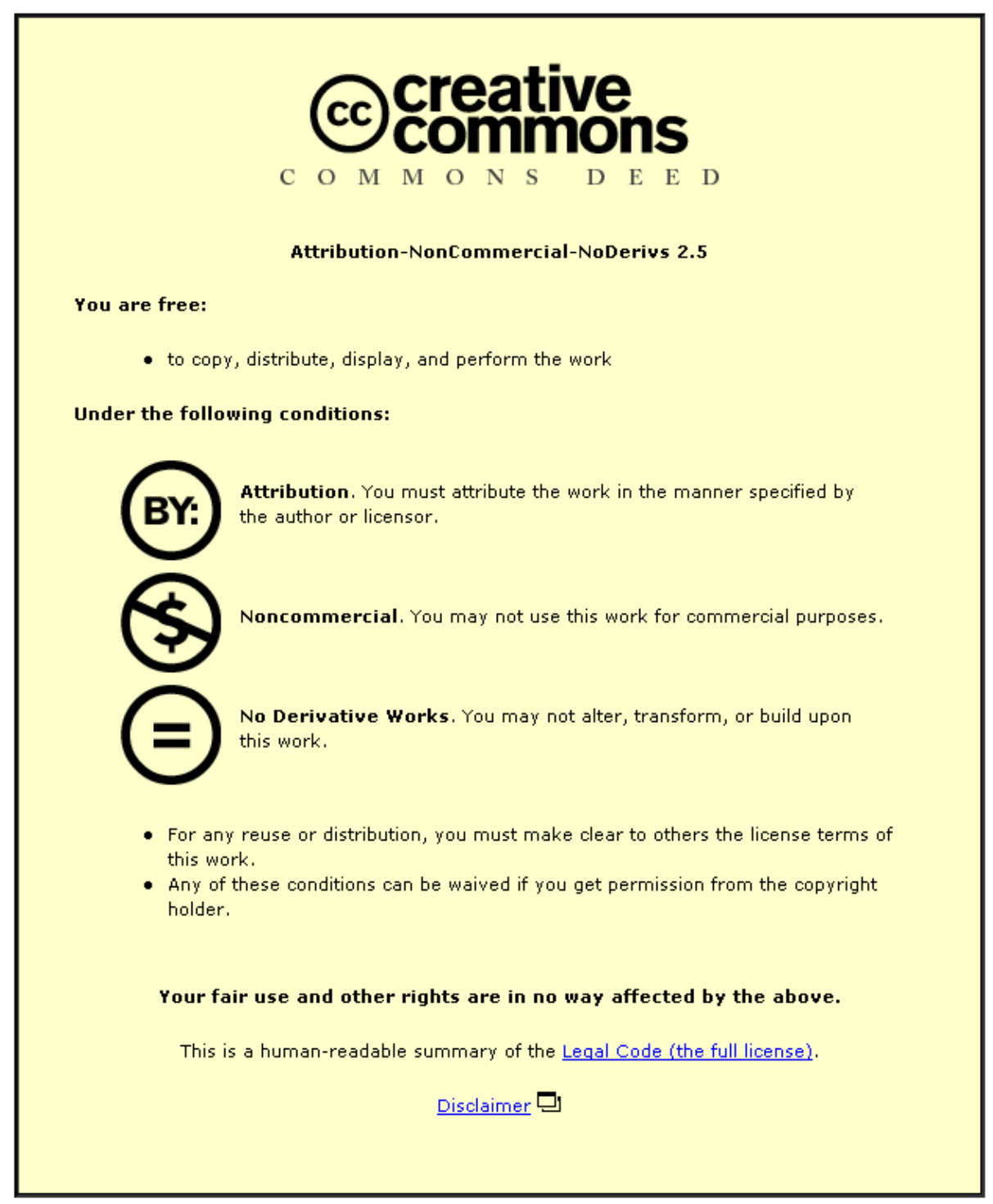

For the full text of this licence, please go to: http://creativecommons.org/licenses/by-nc-nd/2.5/ 
Promoting Stair Climbing: Intervention Effects Generalize to a Subsequent Stair Ascent

Oliver J. Webb*, Frank F. Eves

American Journal of Health Promotion, 2007; 22: 114-119

*corresponding author 


\section{Abstract}

Purpose

Studies report a significant increase in stair use when message prompts are introduced at the 'point-of-choice' between stairs and escalators. Climbing one set of stairs, however, will not confer meaningful health dividends. Therefore, this study examined whether exposure to point-of-choice prompts also encourages individuals to climb the next set of stairs that they encounter.

Design

Interrupted time-series design.

\section{Settings}

Two separate stair/escalator pairings within a UK shopping mall (the 'intervention' site and the 'generalization' site), separated by a $25 \mathrm{~m}$-long atrium.

Subjects

Ascending pedestrians (intervention site $n=29,713$; generalization site $n=47,553$ ).

\section{Interventions}

Two weeks of baseline monitoring were followed by a 13-week intervention in which banners carrying health promotion messages were introduced at the intervention site only.

\section{Measures}

At both sites observers inconspicuously recorded pedestrians' method of ascent, along with their gender, age, ethnicity and baggage.

Results

Banners increased stair climbing at the intervention site by 161\%. Results also suggest a simultaneous increase of up to $143 \%$ at the generalization site, where no prompt was in place. 
At both sites stair use remained significantly elevated five weeks after the banners were removed.

\section{Conclusions}

It appears that exposure to point-of-choice prompts can encourage pedestrians to climb stairs when encountered in a subsequent setting. Consequently, stair climbing interventions are likely to engage the public in more physical activity than previously realised. 


\section{Purpose}

A sedentary lifestyle increases the risk of morbidity and mortality. ${ }^{1-3}$ In industrialised nations, however, up to $75 \%$ of people remain insufficiently active. ${ }^{4,5}$ Alongside health consequences for the individual, sedentariness bears a significant financial burden on society. In the U.S., for example, the annual cost of physical inactivity has been estimated at over $\$ 76$ billion in direct medical expenses alone. ${ }^{6}$ Increasing population activity levels is, therefore, a public health priority. Engaging individuals in exercise has proven difficult, however, as evidenced by persistently low participation rates. ${ }^{7}$ In addition, evidence has emerged that significant health benefits can be derived by accruing moderate intensity activity throughout the day. ${ }^{8}$ Therefore, guidelines from the early 1990s, which emphasised sustained vigorous exercise, have been broadened. Latest recommendations advise a minimum of 30 mins of moderate intensity activity per day, which may be accumulated in 10 minute bouts. ${ }^{9}$

Alongside the change in exercise guidelines a Socio-Ecological model of physical activity promotion has emerged. ${ }^{10-13}$ This approach recognises that the environment and policy decisions can have an important impact on physical activity, in addition to intrapersonal factors (e.g., psychological and biological variables) and interpersonal processes (e.g., social support). Within this framework, interventions to promote stair climbing exemplify how the environment can be exploited to increase physical activity at a population level.

Several studies have successfully increased stair climbing in public-access settings. Typically, posters emphasising the benefits of stair climbing are introduced at the 'point-ofchoice' between stairs and escalators. Such interventions in shopping and commuter venues increased stair climbing relative to baseline by a median value of $68 \%$ (range $=20 \%$ - 
166\%). ${ }^{14-21}$ Even greater increases have been observed when message banners are installed on the stair risers themselves (median=146\%, range $127 \%-179 \%$ ). ${ }^{22-25}$ As a widely accessible, indoor activity stair climbing is free from traditional barriers to exercise such as financial cost, availability of facilities and poor weather. In addition, stair climbing is associated with health dividends such as enhanced cardiorespiratory fitness, improved blood lipid profiles and reduced risk of osteoporosis. ${ }^{26,27}$ Hence, health agencies in North America and the U.K. have acknowledged the potential public health gains from promoting stair climbing. $^{28-30}$

Previous studies report high levels of baseline escalator use, with an average of only $5.5 \%$ of pedestrians climbing the stairs. ${ }^{31}$ Thus, it seems unlikely that every time an individual mounts an escalator he/she makes a deliberate decision to do so. ${ }^{23}$ Rather, taking the escalator instead of the stairs becomes a habit. When habits become firmly entrenched the presentation of familiar environmental cues can be sufficient to elicit behavior relatively automatically, without need for conscious deliberation. ${ }^{32-35}$ Thus, on encountering the classic point-ofchoice scenario of adjacent stairs and escalators, individuals may proceed up the escalator in a 'mindless' fashion. In stair climbing interventions the posters/banners disturb the predictable physical environment, so encouraging conscious thought which may result in a reasoned decision to climb the stairs.

Climbing a single set of stairs, however, is not sufficient to derive significant health benefits. The ultimate goal is to change pedestrians' habits, replacing escalator use with regular choice of the stairs. Stair climbing is a physiologically vigorous activity, requiring 8.6-9.6 times the energy used at rest. ${ }^{36,37}$ Encouraging individuals to accumulate bouts of stair climbing could, therefore, have an important impact on public health. For example, it is estimated that 
climbing stairs for seven minutes each day would expend the equivalent energy required to reduce the ten-year risk of coronary death by $62 \%$ and all-cause mortality by $47 \%{ }^{38} \mathrm{~A}$ first step towards realizing regular stair usage amongst the general public is to test whether pointof-choice prompts have effects beyond the stairs on which they are placed. That is, does the disruption of habitual behaviour by message prompts at one site 'generalize', such that pedestrians also choose the stairs in a subsequent situation? A companion study provides tentative support for such an effect. ${ }^{39}$ In that study, however, an increase in stair descent amongst pedestrians returning to the intervention site was taken as evidence of generalization. The physiological cost of stair descent is only around 1/3 of that incurred during ascent. ${ }^{36,37}$ Thus, the target outcome remains stair climbing.

This study sought to clarify whether point-of-choice prompts produce a generalized increase in ascending stair use beyond the intervention setting. Stair/escalator choices were monitored at two separate point-of-choice sites within the same venue, one of which was fitted with message prompts. The results have important implications for the efficacy of stair climbing as a means of raising population activity levels.

\section{Method}

\section{Design}

A quasi-experimental interrupted time-series design was employed. Ascending stair/escalator use was monitored at two separate point-of-choice locations within a UK shopping centre. The ‘intervention’ site comprised a 24-step staircase and adjacent escalators, leading from the basement level to the first floor. The 'generalization' site consisted of an 18-step staircase and adjacent escalators, linking the first and second floors. All steps were $17 \mathrm{~cm}$ high. Each 
site was bordered by a different selection of retail outlets and, whereas the intervention site was subterraneous, the generalization site was open to natural light. The sites were connected by a 25-metre atrium with a coffee shop in the middle such that they were not visible from each other. This atrium was also accessible from other parts of the shopping complex. As such, it was possible for pedestrians to reach the generalization site without necessarily having passed through the intervention site. Thus, pedestrian traffic at the generalization site was $60 \%$ greater than at the intervention site. A two-week baseline period was followed by a 13-week intervention.

\section{Sample}

Over the course of the study 29,713 and 47,553 pedestrians, respectively, were observed at the intervention and generalization sites. In addition, a convenience sample of 532 pedestrians were interviewed in order to assess their recall of the intervention.

\section{Measures}

Using a pool of four alternating observers pedestrians’ behavior was simultaneously monitored at both sites. In each case an investigator stood near the top of the stairs/escalator at a perpendicular angle such that they were out of view of pedestrians boarding below. Observers recorded whether individuals ascended the stairs or escalator and coded their gender, age, ethnicity and baggage using the protocol defined by Kerr et al. ${ }^{23}$ At both sites data were collected on Tuesday and Friday, between 12.30 and 16:00, so to include lunch and daytime users. Observations were taken in weeks 1-4 of the banner phase and again in week 13, so as to assess any adaptation to the messages over time. A further two weeks of followup observations were made five weeks after the intervention was removed. 
During the banner phase a convenience sample of pedestrians were interviewed at each site. Investigators approached individuals as they finished ascending the stairs/escalator and asked if they were willing to take part in a brief interview. Participation was entirely voluntary. At the intervention site 222 escalator users and 170 stair users were approached, from which 112 and 83, respectively, agreed to respond. At the generalization site 337 escalator users and 567 stair users were similarly approached, from which 103 and 234, respectively, agreed to respond. Interviewees were asked, "Do you recall seeing banners attached to the stairs in this shopping centre?”. Those who reported seeing the banners were then asked, “Can you recall what the banners said?”. One point was available for recalling each of the three messages featured. Points were awarded for perfect responses and those which were semantically correct.

\section{Intervention}

Two weeks of baseline monitoring were followed by thirteen weeks in which message banners were installed at the intervention site only (see Figure 5.1). From the top, the prompt “Take the stairs” was followed by three different messages; "Stair climbing burns more calories per minute than jogging”, “7 minutes of stair climbing per day protects your heart” and "Stair climbing burns more calories per minute than tennis". The message content was decided in light of research which suggests that messages focussing on specific health consequences may be most effective in increasing stair use. ${ }^{40}$

\section{Analysis}

Observational data from each site was analysed separately using logistic regression analyses. Stair/escalator use served as the dichotomous outcome variable. Gender, age, ethnicity, baggage and pedestrian traffic volume were also included in all models, having previously 
been shown to have important effects. ${ }^{14-17,19-23,25}$ For the interview data, Chi-square tests were used to check for any differences in response rate by site and stair/escalator use. In addition, respective percentage recall rates were calculated for each of the three messages.

\section{Figure 5.1: Message banners at the intervention site}

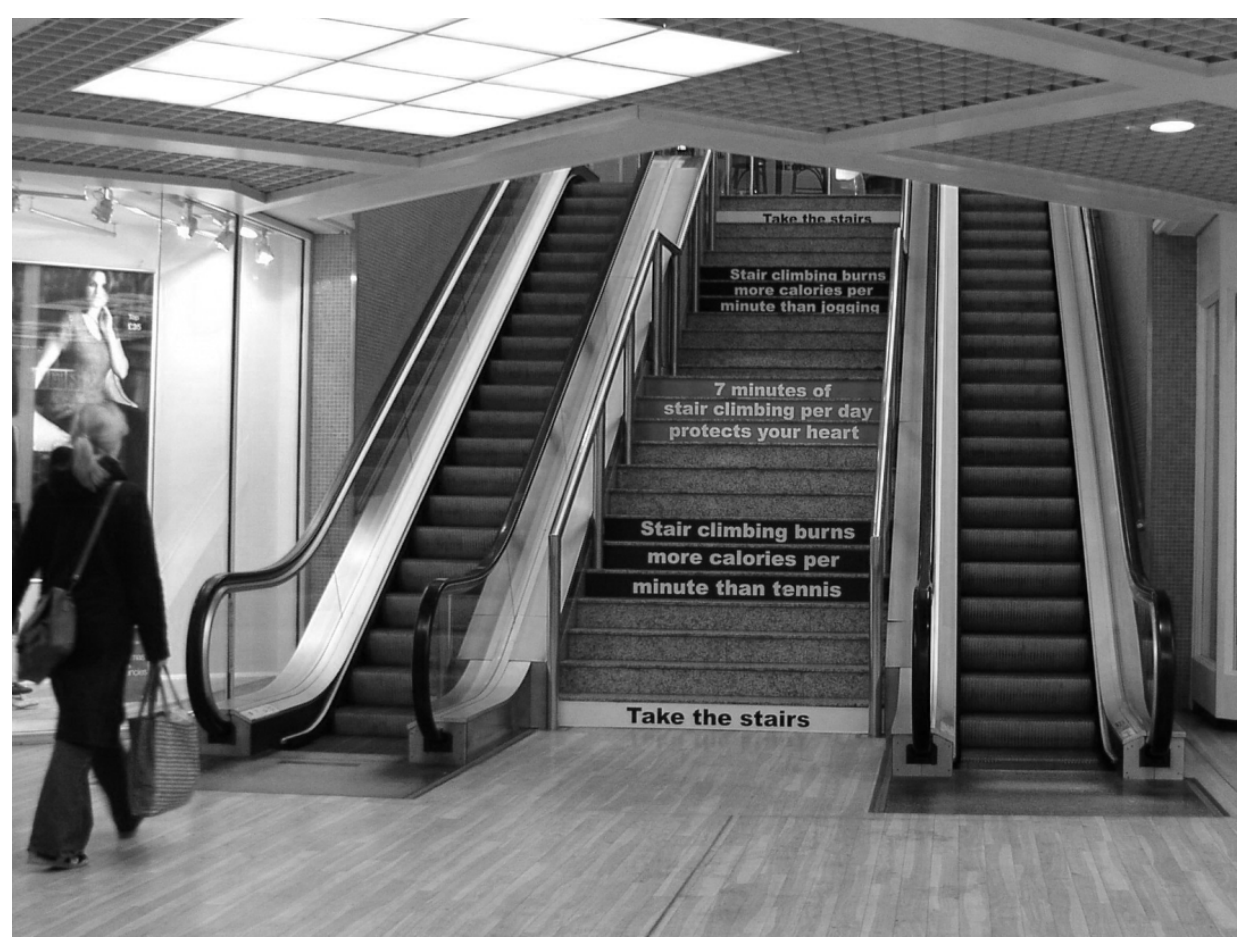

\section{Results}

Inter-observer agreement was 100\% for stair/escalator use, 99\% for gender, $94 \%$ for age, $97 \%$ for ethnicity and $97 \%$ for baggage. Of the pedestrians observed at the intervention site $46 \%$ were male, $68 \%$ were White and $84 \%$ were classified as under 60 years old. At the generalization site $39 \%$ of pedestrians were male, $76 \%$ were White and $89 \%$ were classified as under 60 years old. 
Throughout the duration of the study significant demographic effects were observed at both sites, such that men (intervention site: odds ratio $[\mathrm{OR}]=1.39$, 95\% confidence interval $[C I]=1.29,1.50$; generalization site: $\mathrm{OR}=1.45,95 \% \mathrm{CI}=1.37,1.52)$, those aged under 60 (intervention site: $\mathrm{OR}=2.65, \mathrm{CI}=2.32$, 3.04; generalization site: $\mathrm{OR}=2.93, \mathrm{CI}=2.63,3.27$ ) and White persons (intervention site: $\mathrm{OR}=2.01, \mathrm{CI}=1.89,2.26$; generalization site: $\mathrm{OR}=1.64$, $\mathrm{CI}=1.54,1.74)$ climbed the stairs more than their counterparts. There were also significant effects of baggage, such that unencumbered people climbed the stairs more than those with large bags (intervention site: $\mathrm{OR}=1.46, \mathrm{CI}=1.26,1.69$; generalization site: $\mathrm{OR}=1.47, \mathrm{CI}=1.35$, 1.61). There were, however, no significant interactions between demographics/baggage and the banner or follow-up phases. Finally, a significant effect of pedestrian traffic was observed at both sites (both $p<.05$ ), such that more people used the stairs during busy periods.

\section{Figure 5.2: Percentage stair use at the intervention and generalization sites during baseline, banner exposure and follow-up}

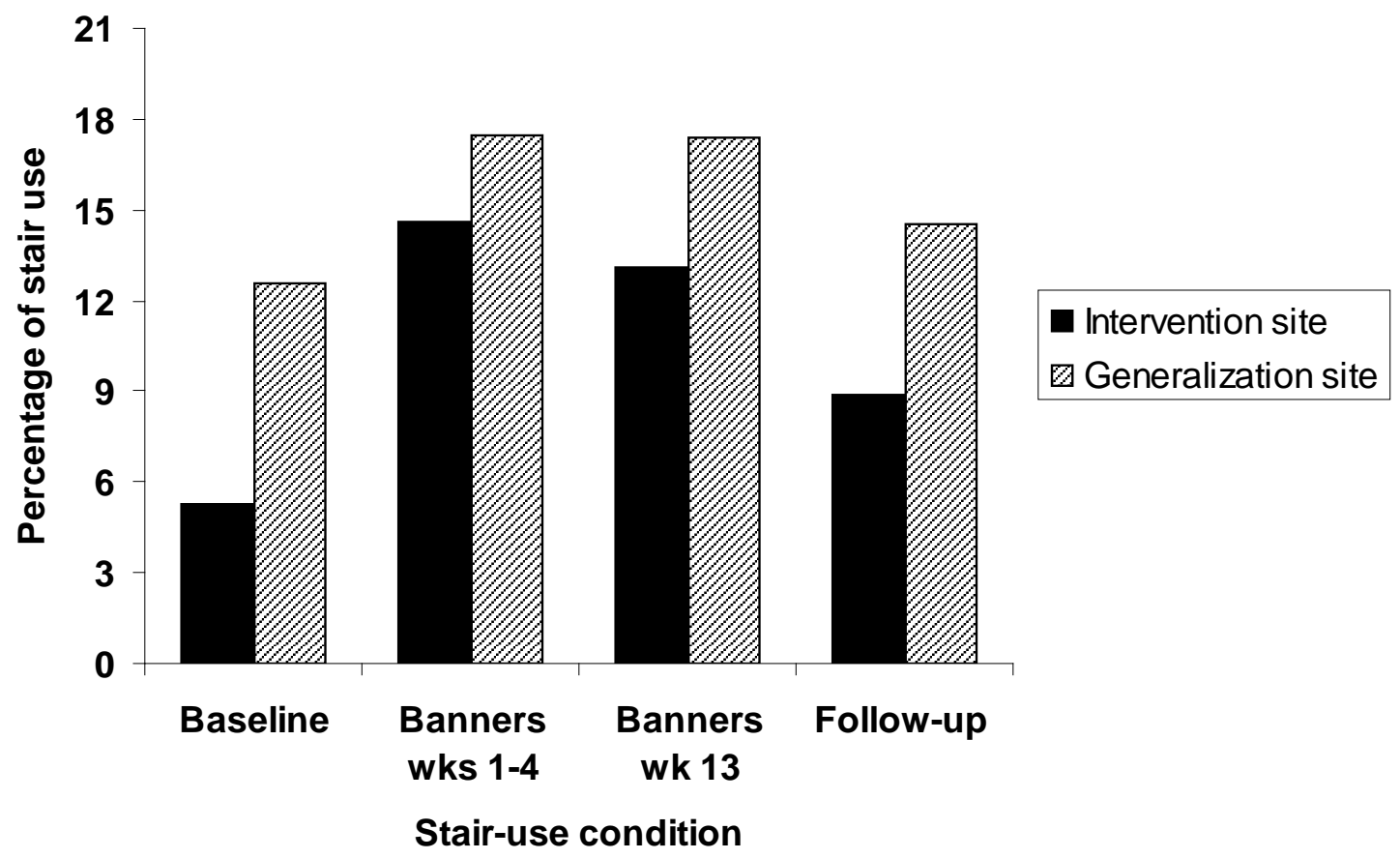

Figure 5.2 shows percentage stair use at each site over the course of the study. At the intervention site stair climbing increased significantly from 5.3\% at baseline to $14.6 \%$ during 
weeks $1-4$ of the banners $(\mathrm{OR}=2.76, \mathrm{CI}=2.44,3.12)$. There was also a significant increase in stair climbing at the generalization site, from $12.6 \%$ at baseline to $17.5 \%$ during weeks $1-4$ $(\mathrm{OR}=1.39, \mathrm{CI}=1.29,1.49)$. This effect at the generalization site represents a conservative estimate. Over the same period, the volume of pedestrian traffic at the generalization site was $60 \%$ higher than at the intervention site. Thus, many of the pedestrians observed at the generalization site would not have been exposed to the point-of-choice prompt and hence could not have been prompted to increase their stair use. To more accurately estimate the effect of the prompt at the generalization site, the OR was adjusted to control for pedestrians who could not have seen it. The number of stair users observed at the generalization site during the first four weeks of the intervention was expressed as a percentage of the people who had been exposed to the messages (i.e. total pedestrian traffic at the intervention site over the same time period). This percentage was then converted to an OR relative to baseline stair usage at the generalization site. The adjusted OR of 2.47 represents an upper bound for the effect of the prompt at the generalization site.

To assess the durability of the effects, weeks 1-4 of the banners were compared with week 13. There was no significant change in stair use, either at the intervention site $(\mathrm{OR}=0.91$, $\mathrm{CI}=0.81,1.03)$ or generalization site $(\mathrm{OR}=0.97, \mathrm{CI}=0.88,1.06)$. Therefore, analyses were repeated with data from weeks 1-4 and week 13 collapsed. Over the full 13-week course of the prompt, stair use at the intervention site increased by an OR of $2.61(\mathrm{CI}=2.32,2.94)$. As before, we calculated an adjusted estimate for the effects of the prompt at the generalization site. The adjusted OR of 2.43 over the full duration of the intervention indicates a substantial increase in stair climbing at the generalization site. 
In order to assess any decline in stair usage following removal of the intervention, the collapsed data from weeks 1-4 and week 13 was compared with the follow-up data collected five weeks after the point-of-choice prompt was withdrawn. There was a significant drop in stair climbing at the intervention site $(\mathrm{OR}=0.63, \mathrm{CI}=0.55,0.74)$ and generalization site $(\mathrm{OR}=0.84, \mathrm{CI}=0.76,0.92)$ after the banners were removed. Further analyses showed, however, that stair use during follow-up remained significantly higher than at baseline, both at the intervention site $(\mathrm{OR}=1.67, \mathrm{CI}=1.44,1.94)$ and the generalization site $(\mathrm{OR}=1.15$, $\mathrm{CI}=1.06,1.26)$.

Chi-square analyses of the interview data revealed that pedestrians at the intervention site were more likely to respond than their counterparts at the generalization site $\left(\chi^{2}=17.6, \mathrm{df}=1\right.$, $p<0.001$ ). There was, however, no significant difference in response rate between stair users and escalator users. Of the people interviewed at the intervention site $80.0 \%$ reported seeing the banners (escalator users=66.1\%; stair users=98.8\%), of whom $89.8 \%$ could remember the content of at least one of the messages. The individual recall rates for the three messages were highly consistent; “...jogging” (57.7\%), “7 minutes...” (56.4\%) and “...tennis” (53.2\%). At the generalization site $44.0 \%$ of interviewees reported seeing the banners (escalator users $=25.5 \%$; stair users $=52.1 \%$ ), with $88.6 \%$ of these able to recollect the content of one or more message. Again, consistent recall rates were observed for each of the three messages; “...jogging” (56.1\%), “7 minutes...” (54.7\%) and “...tennis” (38.5\%).

\section{Discussion}

Over the 13-week lifespan of the point-of-choice prompt there was a $161 \%$ increase in stair climbing at the intervention site. Consistent with four earlier studies which featured stair-riser 
banners, this increase is considerably greater than reported for conventional posters. ${ }^{22-25}$ The impact of our intervention, at the top end of the range of previously reported effects, may reflect the messages used. We selected messages which emphasised specific health consequences of stair climbing. Recent findings indicate that this type of message may be more effective than the general descriptions employed in previous studies e.g., "free exercise”, “easy exercise”. 40

Crucially, during the banner phase there was also a significant increase in stair climbing at the generalization site, in the absence of any visible prompt to do so. This finding corroborates previous evidence that interventions can encourage pedestrians to use the stairs when they encounter a subsequent point-of-choice scenario. ${ }^{39}$ Owing to the layout of the venue, a proportion of the pedestrians observed at the generalization site could not have seen the point-of-choice prompt. Correcting for this group suggests that over the 13-week duration of the prompt stair use at the generalization site may have risen by as much as $143 \%$ amongst those who were exposed to it. This effect compares favourably with the $161 \%$ increase observed at the intervention site. Thus, it appears that the majority of people who responded to the prompt at the intervention site also climbed the stairs when they reached the generalization site. Significantly, the intervention and generalization sites differed in terms of the height of the ascent (24 steps versus 18 steps), the lighting conditions and the adjoining shops. Thus, it appears that generalization effects can occur between point-of-choice settings which are contextually different.

The differing pattern of stair/escalator use between the experimental sites merits comment. Whilst the point-of-choice prompt was effective at both sites, stair use at the intervention site was lower per se than at the generalization site. A recent review of worksite interventions 
found an appreciable negative correlation between the baseline rate of stair climbing and the number of storeys in a building. ${ }^{31}$ Interview data from a previous study also indicates that the height of a climb influences individuals' willingness to use the stairs. ${ }^{41}$ Thus, in the current study it seems likely that fewer people overall climbed the intervention staircase because it was higher than the generalization staircase (24 steps vs. 18 steps).

It is important to consider how the message banners increased stair climbing at the generalization site. Here it is pertinent to distinguish between the concepts of disrupting habitual escalator use and establishing a new habit of stair use. Escalator use is a frequently performed behavior and is thus likely to be a firmly held habit. ${ }^{34,42}$ Therefore, we think it unlikely that initial exposure to the point-of-choice prompt changed pedestrians’ habitual tendencies such that they climbed the stairs at the generalization site in a 'mindless' fashion. Thus, on its own it would be unwise to interpret the increased rate of stair climbing at the generalization site as evidence of a newly formed habit. A more plausible explanation is that individuals assimilated the information contained within the prompt and this continued to disrupt their habitual behavior when they reached the generalization site. Hence, individuals made a conscious decision to take the stairs. Indeed, interview data from the generalization site confirms that people retained necessary information to make a reasoned decision; almost $90 \%$ of those who reported seeing the banners could successfully recall the content of at least one of the messages.

For health promoters the ultimate objective is not merely to disrupt 'bad' habits but to change individuals' habitual behavior in favour of new more adaptive alternatives. As such, it is notable that stair use at both the intervention site and generalization site remained

\footnotetext{
* We thank an anonymous reviewer for suggesting that we clarify this important distinction
} 
significantly elevated even five weeks after the point-of-choice prompt was removed. These results must reflect a sustained change in behavior amongst people who were exposed to the intervention during a previous visit to the venue. Our findings coincide with Blamey et al. who found that stair use remained significantly higher than at baseline, up to 12 weeks after they withdrew their intervention. ${ }^{15}$ The persistence of these effects over the medium-term implies that it may be feasible to change individuals' behavioral tendencies in favour of stair use. If future studies can demonstrate that post-intervention effects survive into the longerterm, this would provide plausible evidence that exposure to message prompts can engender a new habit of stair use.

Important questions remain. Whilst we calculated corrected estimates from the data collected at the generalization site, it is important to establish the true magnitude of generalization effects. Hence, this study should be repeated in a venue where access between the intervention and generalization sites is enclosed, so as to ensure that pedestrians are exposed to the banners. Furthermore, whilst Verplanken et al. also succeeded in disrupting individuals’ habitual travel choices, they found that effects deteriorated over time. ${ }^{43}$ It is, therefore, essential to ascertain if generalization effects diminish as a function of time or distance from the initial intervention setting. Additionally, there may be confounding variables that influence stair/escalator use which we did not account for in the current study. For instance, Eves and Masters recently reported findings from their study of the Hong Kong Mid-Levels system, a network of travellators (i.e. sloping escalators without steps) aimed at reducing motorized traffic throughout the city. ${ }^{44}$ Different patterns of behavior were observed on weekdays versus weekends and at midday compared with evening time. It seems plausible, therefore, that pedestrians' stair/escalator choices may similarly fluctuate 
throughout the course of the week. Thus, future stair climbing studies may benefit from counter-balancing the days and times when observations are made.

The current findings have important practical implications. The health dividends of regular stair climbing are well documented, whilst evidence also exists for a possible dose-response relationship between stair use and mortality. ${ }^{45}$ Thus, the more stairs people climb the more their health should benefit. Our findings confirm that exposure to a point-of-choice prompt can encourage people to use the stairs when the opportunity next arises. The health outcomes of individual interventions could, therefore, be much greater than previously realised. This study suggests that it may be feasible to effect a meaningful increase in population stair climbing without a blanket campaign of prompts at every choice point, which would be both costly and complicated to deploy. Given the onus on health promotion practitioners to deliver value for money, these findings strengthen the case for further investment in stair climbing initiatives.

The emergent Socio-Ecological approach to physical activity promotion represents a shift in emphasis, from determinants of individual exercise participation to how the built environment can influence physical activity at a population level. The present study demonstrates that message banners can not only increase stair use at the immediate intervention site but also at the next choice point that pedestrians encounter. Further research is needed to explore how we can best exploit these generalization effects to realize optimum rates of stair climbing. Nonetheless, our findings provide preliminary evidence that simple and inexpensive campaigns of sporadically placed message prompts may achieve widespread and meaningful growth in stair usage. 


\section{SO WHAT?}

Stair climbing is a widely accessible form of physical activity with proven health benefits. Although several studies show that it is possible to encourage pedestrians to use the stairs rather than the escalator, climbing a single flight will not confer meaningful health benefits. The aim must be to encourage individuals to climb the stairs whenever they encounter an opportunity to do so. This study shows that exposure to message prompts at one stair/escalator location can also encourage stair use at a different stair/escalator site within the same mall. Thus, it appears that intervention effects endure beyond the initial exposure, engaging individuals in more physical activity than previously realised. It may be feasible, therefore, to achieve widespread growth in stair usage with simple and inexpensive campaigns of sporadically placed message prompts. 


\section{References}

1. Booth FW, Gordon SE, Carlson CJ, Hamilton M.T. Waging war on modern chronic diseases: primary prevention through exercise biology. J Appl Physiol. 2000;88:774-787.

2. Myers J, Kaykha A, George S, et al. Fitness versus physical activity patterns in predicting mortality in men. Am J Med. 2004;117:912-918.

3. Warburton DER, Nicol CW, Bredin SSD. Health benefits of physical activity: the evidence. CMAJ. 2006;174:801-807.

4. National Health Interview Survey 2005. Hyattsville, MD. National Center for Health tatistics. Centers for Disease Control and Prevention; 2005.

5. Health Survey for England 2003. London: Office for National Statistics. The Stationary Office; 2004

6. Pratt M, Macera CA, Wang G. Higher direct medical costs associated with physical inactivity. Phys Sportsmed. 2000;28:63-70.

7. Dunn AL, Andersen RE, Jakicic JM. Lifestyle physical activity interventions: History, short- and long-term effects, and recommendations. Am J Prev Med. 1998;15:398-412.

8. Pate RR, Pratt M, Blair SN, et al. Physical activity and public health. A recommendation from the Centers for Disease Control and Prevention and the American College of Sports Medicine. JAMA. 1995;273:402-407.

9. Physical Activity and Health: A Report of the Surgeon General. Atlanta, GA: National Centre for Chronic Disease Prevention and Health Promotion. Centers for Disease Control and Prevention; 1996. 
10. Owen N, Humpel N, Leslie E, Bauman A, Sallis JF. Understanding environmental influences on walking: Review and research agenda. Am J Prev Med. 2004;27:67-76.

11. Sallis JF, Bauman A, Pratt M. Environmental and policy interventions to promote physical activity. Am J Prev Med. 1998;15:379-397.

12. Stokols D. Translating social ecological theory into guidelines for community health promotion. Am J Health Promot. 1996;10:282-298.

13. Zimring C, Joseph A, Nicoll GL, Tsepas S. Influences of building design and site design on physical activity: Research and intervention opportunities. Am J Prev Med. 2005;28:186-193.

14. Andersen RE, Franckowiak SC, Snyder J, Bartlett SJ, Fontaine KR. Can inexpensive signs encourage the use of stairs? Results from a community intervention. Ann Intern Med. 1998;129:363-369.

15. Blamey A, Mutrie N, Aitchison T. Health promotion by encouraged use of stairs. $\mathrm{Br}$ Med J. 1995;311:289-290.

16 Brownell KD, Stunkard AJ, Albaum JM. Evaluation and modification of exercise patterns in the natural environment. Am J Psychiatry. 1980;137:1540-1545.

17. Coleman KJ, Gonzalez EC. Promoting stair use in a US-Mexico border community. Am J Public Health. 2001;91:2007-2009.

18. Kerr J, Eves FF, Carroll D. Posters can prompt less active people to use the stairs. $J$ Epidemiol Community Health. 2001;54:942-943.

19. Kerr J, Eves FF, Carroll D. The influence of poster prompts on stair use: the effects of setting, poster size and content. Br J Health Psychol. 2001;6:397-405. 
20. Mutrie N, Blamey A, Aitchison T. Why do fewer women choose stairs? J Sport Sci. 1996;14:16-17.

21. Russell WD, Hutchison J. Comparison of health promotion and deterrent prompts in increasing use if stairs over escalators. Percept Mot Skills. 2000;91:55-61.

22. Kerr J, Eves FF, Carroll D. Getting more people on the stairs: the impact of a new message format. J Health Psychol. 2001;6:495-500.

23. Kerr J, Eves FF, Carroll D. Six-month observational study of prompted stair climbing. Prev Med. 2001;33:422-427.

24. Kerr J, Eves FF, Carroll D. Encouraging stair use: stair-riser banners are better than posters. Am J Public Health. 2001;91:1192-1193.

25. Webb OJ, Eves FF. Promoting stair use: single versus multiple stair-riser messages. Am J Public Health. 2005;95:1543-1544.

26. Boreham CAG, Kennedy RA, Murphy MH, Tully M, Wallace WFM, Young I. Training effects of short bouts of stair climbing on cardiorespiratory fitness, blood lipids, and homocysteine in sedentary young women. Br J Sports Med. 2005;39:590-593.

27. Coupland CA, Cliffe S J, Bassey E J, Grainge MJ, Hosking DJ, Chilvers, CED. Habitual physical activity and bone mineral density in postmenopausal women in England. Int J Epidemiol. 1999;28:241-246.

28. Department of Health. At least five times a week: Evidence on the impact of physical activity and its relationship to health. A report from the Chief Medical Officer. London: Department of Health, 2004 
29. Department of Health and Human Services, Centres for Disease Control and Prevention. StairWELL to Better Health: A Worksite Intervention. Available at: http://www.cdc.gov/nccdphp/dnpa/stairwell/index.htm. Accessed October 13, 2004.

30. Edwards P. Stair walking...a few steps to better health. Can J Public Health. 1983;74:63-65.

31. Eves FF, Webb OJ. Worksite interventions to increase stair climbing; Reasons for caution. Prev Med. 2006;43:4-7.

32. Aarts H, Paulussen T, Schaalma H. Physical exercise habit: on the conceptualization and formation of habitual health behaviours. Health Educ Res. 1997;12:363-374.

33. Aarts H, Verplanken B, van Knippenberg A. Habit and information use in travel mode choices. Acta Psychol. 1997;96:1-14.

34. Oulette JA, Wood W. Habit and intention in everyday life: The multiple processes by which past behavior predicts future behavior. Psychol Bull. 1998;124:54-74.

35. Wood W, Tam L, Witt MG. Changing circumstances, disrupting habits. J Pers Soc Psychol. 2005;88:918-933.

36. Bassett DR, Vachon JA, Kirkland AO, Howley ET, Duncan GE, Johnston KR. Energy cost of stair climbing and descending on the college alumnus questionnaire. Med Sci Sports Exerc. 1997;29:1250-1254.

37. Teh KC, Aziz AR. Heart rate, oxygen uptake, and energy cost of ascending and descending the stairs. Med Sci Sports Exerc. 2002;34:695-699.

38. Yu S, Yarnell JWG, Sweetnam PM, Murray L. What level of physical activity protects against premature cardiovascular death? The Caerphilly study. Heart. 2003;89:502506. 
39. Webb OJ, Eves FF. Effects of environmental changes in a stair climbing intervention: generalization to stair descent. Am J Health Promot. In press.

40. Webb OJ, Eves FF. Promoting stair climbing: Effects of message specificity and validation. Health Educ Res. In press.

41. Kerr J, Eves FF, Carroll D. Can posters prompt stair use in a worksite environment? J Occup Health 2001;43 205-207

42. Aarts H, Dijksterhuis AP. The automatic activation of goal-directed behaviour: The case of travel habit. J Environ Psychol. 2000;20:75-82.

43. Verplanken B, Aarts H, van Knippenberg A. Habit, information acquisition, and the process of making travel mode choices. Eur J Soc Psychol. 1997;27:539-560.

44. Eves FF, Masters RSW. An uphill struggle: Effects of a point-of-choice stair climbing intervention in a non-English speaking population. Int J Epidemiol. 2006;35:1286-1290.

45. Paffenbarger RS, Hyde RT, Wing AL, Lee I-M, Mapert JB. In Bouchard C, Shepherd RJ, Stephens T, eds. Physical Activity, Fitness and Health. Champaign, IL: Human Kinetics; 1994:119-133. 